\title{
A Biomimetic Model for Liver Cancer to Study Tumor- Stroma Interactions in a 3D Environment with Tunable Bio-Physical Properties
}

\author{
Carlemi Calitz ${ }^{1}$, Nataša Pavlović ${ }^{1}$, Jenny Rosenquist ${ }^{2}$, Claudia Zagami $^{1}$, Ayan Samanta ${ }^{2}$, Femke Heindryckx ${ }^{1}$ \\ ${ }^{1}$ Department of Medical Cell Biology, Uppsala University ${ }^{2}$ Polymer Chemistry, Department of Chemistry-Ångström Laboratory, Uppsala University
}

\section{Corresponding Author}

Femke Heindryckx

femke.heindryckx@mcb.uu.se

\section{Citation}

Calitz, C., Pavlović, N., Rosenquist, J., Zagami, C., Samanta, A.,

Heindryckx, F. A Biomimetic Model for Liver Cancer to Study Tumor-Stroma Interactions in a 3D Environment with Tunable Bio-Physical Properties. J. Vis. Exp. (162), e61606, doi:10.3791/61606 (2020).

\section{Date Published}

August 7, 2020

DOI

$10.3791 / 61606$

URL

jove.com/video/61606

\section{Abstract}

Hepatocellular carcinoma $(\mathrm{HCC})$ is a primary liver tumor developing in the wake of chronic liver disease. Chronic liver disease and inflammation leads to a fibrotic environment actively supporting and driving hepatocarcinogenesis. Insight into hepatocarcinogenesis in terms of the interplay between the tumor stroma microenvironment and tumor cells is thus of considerable importance. Three-dimensional (3D) cell culture models are proposed as the missing link between current in vitro 2D cell culture models and in vivo animal models. Our aim was to design a novel 3D biomimetic HCC model with accompanying fibrotic stromal compartment and vasculature. Physiologically relevant hydrogels such as collagen and fibrinogen were incorporated to mimic the bio-physical properties of the tumor ECM. In this model LX2 and HepG2 cells embedded in a hydrogel matrix were seeded onto the inverted transmembrane insert. HUVEC cells were then seeded onto the opposite side of the membrane. Three formulations consisting of ECM-hydrogels embedded with cells were prepared and the bio-physical properties were determined by rheology. Cell viability was determined by a cell viability assay over 21 days. The effect of the chemotherapeutic drug doxorubicin was evaluated in both 2D co-culture and our 3D model for a period of $72 \mathrm{~h}$. Rheology results show that bio-physical properties of a fibrotic, cirrhotic and HCC liver can be successfully mimicked. Overall, results indicate that this $3 \mathrm{D}$ model is more representative of the in vivo situation compared to traditional $2 \mathrm{D}$ cultures. Our $3 \mathrm{D}$ tumor model showed a decreased response to chemotherapeutics, mimicking drug resistance typically seen in HCC patients.

\section{Introduction}

Hepatocellular carcinoma (HCC) comprises $90 \%$ of all primary liver cancers ${ }^{1,2}$. With 810,000 deaths and 854,000 new cases reported annually it is currently ranked as the fifth most common cancer worldwide with one of 
the highest incidences of mortality ${ }^{1}$. The development of $\mathrm{HCC}$ is predominantly attributed to inflammation associated with chronic liver diseases namely, viral hepatitis, chronic excessive alcohol intake, metabolic syndrome, obesity and diabetes $^{1,3,4}$. The inflammation associated with these pathological conditions results in hepatocyte injury and secretion of various cytokines that activate and recruit hepatic stellate cells and inflammatory cells to initiate fibrosis ${ }^{5}$. Hepatic stellate cells are known for their key role in the initiation, progression, and regression of hepatic fibrosis. Upon activation they differentiate into myofibroblast like cells with contractile, pro-inflammatory and pro-fibrinogenic properties $^{6,7,8}$. The resulting fibrosis in turn causes the dysregulation of extracellular matrix remodeling enzyme activity, creating an environment characterized by an overall increased stiffness accompanied by the secretion of growth factors, which further contributes to HCC pathogenesis ${ }^{9}, 10$. It is this continuous pathogenic feedback loop between hepatocytes and the stromal environment, which fuels cancer initiation, epithelial to mesenchymal transitions (EMT), angiogenesis, metastatic potential, and altered drug response $11,12,13$. Insight into hepatocarcinogenesis in terms of the interplay between the tumor and the tumor micro-environment is, therefore, of considerable importance not only from a mechanistic but also from a treatment perspective.

Two-dimensional (2D) in vitro cell culture models are predominantly used by $80 \%$ of cancer cell biologists ${ }^{14}$. However, these models are not representative of the true tumor micro-environment, which affects chemotherapeutic responses ${ }^{14,15,16}$. Currently $96 \%$ of chemotherapeutic drugs fail during clinical trials ${ }^{14}$. This high incidence in drug attrition rates can be attributed to the fact that available in vitro pre-screening models do not fully represent our current insight and understanding of HCC complexity and the microenvironment ${ }^{16}$. Conversely in vivo animal models present with compromised immune systems and discrepancies in interactions between the tumor and the microenvironment when compared to humans ${ }^{16,17}$. On an average only $8 \%$ of results obtained from animal studies can be reliably translated from the pre-clinical to the clinical setting ${ }^{16}, 17$. Therefore, it is clear that the evaluation of HCC requires the development of an in vitro platform that effectively recapitulates the complexity of not only the tumor but also the microenvironment. The platforms would supplement the currently available in vitro pre-clinical screening models and reduce the amount of animal studies in the future ${ }^{7,14}$.

One such platform is advanced three-dimensional (3D) cell culture models. A multitude of these advanced 3D models to study HCC have emerged over the last decade and various reviews have been published. Available 3D models to study HCC include multicellular spheroids, organoids, scaffold-based models, hydrogels, microfluidics, and bioprinting. Of these, multicellular spheroids are one of the best-known models used in the study of tumor development. Spheroids are an inexpensive model with low technical difficulty while at the same time effectively mimicking in vivo tumor architecture $18,19,20$. Multicellular spheroids have contributed to a wealth of information on $\mathrm{HCC}^{17,21,22}$. However, standardized culture time is lacking as multicellular spheroids are kept in culture between 7 to 48 days. Increased culture time is of considerable importance. Eilenberger found that the differences in spheroid age profoundly influences Sorafenib (a kinase inhibitor used for the treatment of liver cancers) diffusivity and toxicity ${ }^{23}$. While Wrzesinski and Fey found that $3 \mathrm{D}$ hepatocyte spheroids require 18 days to reestablish key physiological liver functions after trypsinization 
and continues to exhibit the stable functionality for up to 24 days after this recovery 24,25 .

Some of the more advanced 3D HCC models includes the use of human decellularized liver scaffolds and bioprinted scaffolds. Mazza and colleagues created a natural 3D scaffold for HCC modeling using decellularized human livers not suitable for transplantation ${ }^{26}$. These natural scaffolds could successfully be repopulated for 21 days with a co-culture of hepatic stellate and hepatoblastoma cells, while maintaining the expression of key extracellular matrix components such as collagen type I, III, IV and fibronectin. Other than disease modeling, this model also offers the advantage of functional organ transplantation and pre-clinical drug and toxicity screening ${ }^{26}$. With the advances in $3 D$ bio-printing, 3D extracellular matrix scaffolds can now also be bio-printed. Ma and colleagues, bio-printed extracellular matrix scaffolds with variable mechanical properties and biomimetic microarchitecture using hydrogels engineer from decellularized extracellular matrix ${ }^{27}$. Undoubtedly these are all excellent 3D HCC models. However, unavailability of human livers and the cost involved in acquiring the necessary equipment and materials places these models at a disadvantage. Additionally, these methods are all technically advanced requiring extensive training that may not be readily available to all researchers.

Based on the complexity of HCC and currently available 3D models, we endeavored to develop an all-encompassing 3D HCC model. We aimed for a model capable of recapitulating both the premalignant and tumor microenvironment by incorporating adjustable hydrogel stiffness values.

Furthermore, we also included hepatocellular and stroma associated cell lines, that play a key role in the pathogenesis of HCC. These include endothelial cells, hepatic stellate cells and malignant hepatocytes, grown in a microenvironment composed of physiologically relevant hydrogels. With the chosen hydrogels, collagen type I and fibrinogen, incorporated in ratios comparable to bio-physical changes seen in liver stiffness during the initiation and progression of HCC. Additionally, we aimed for a model that could be kept in culture for a prolonged time-period. We envisioned a modular, cost effective model that can be setup with basic equipment, minimal training and experience, and readily available materials.

\section{Protocol}
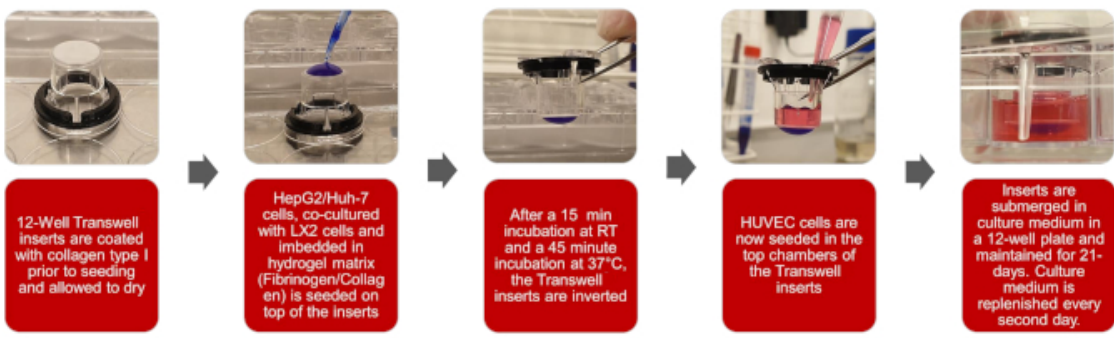

Figure 1: Graphical depictions of the creation of the 3D biomimetic HCC model Please click here to view a larger version of this figure. 
NOTE: The overall workflow of this protocol is set out in the illustrations of Figure 1

\section{Preparation of fibrinogen stock solution}

1. Prepare a $1 \mathrm{M}$ calcium chloride $\left(\mathrm{CaCl}_{2}\right)$ stock solution, by weighing $2.21 \mathrm{~g} \mathrm{CaCl}_{2}$ and adding it to $20 \mathrm{~mL}$ distilled water $\left(\mathrm{dH}_{2} \mathrm{O}\right)$. Stock solution can be stored at room temperature (RT).

2. Prepare a $20 \mathrm{~mL}$ aprotinin stock solution $(1218.75 \mathrm{KIU} /$ $\mathrm{mL}$ ) by weighing $5 \mathrm{mg}$ of aprotinin and adding it to $20 \mathrm{~mL}$ $\mathrm{dH}_{2} \mathrm{O}$. Aliquot stock solution into $1 \mathrm{~mL}$ aliquots and store at $-20{ }^{\circ} \mathrm{C}$.

3. Prepare a $10 \mathrm{~mL}$ of $80 \mathrm{mg} / \mathrm{mL}$ fibrinogen stock solution.

1. In a $50 \mathrm{~mL}$ tube add $7.849 \mathrm{~mL}$ phosphate buffered saline (PBS), $2.051 \mathrm{~mL}$ aprotinin stock (1218.75 KIU/ $\mathrm{mL}$ ) for a final aprotinin concentration of $250 \mathrm{KIU} / \mathrm{mL}$ and $100 \mu \mathrm{L} \mathrm{CaCl}_{2}(1 \mathrm{M})$ for a final $\mathrm{CaCl}_{2}$ concentration of $10 \mathrm{mM}$.

2. Weigh $800 \mathrm{mg}$ of fibrinogen.

3. Weigh $200 \mathrm{mg}$ sodium chloride $(\mathrm{NaCl})$ for the stock solution to contain $2 \% \mathrm{w} / \mathrm{v} \mathrm{NaCl}$.

4. Add the fibrinogen and $\mathrm{NaCl}$ in increments to the 50 $\mathrm{mL}$ tube containing the PBS, aprotinin and $\mathrm{CaCl}_{2}$. Do not stir or shake vigorously as this will result in fibrinogen gelling and lumps forming in the solution.

5. Place the $50 \mathrm{~mL}$ tube of the fibrinogen stock solution horizontally on a shaker and shake at a low setting of $300 \mathrm{rpm}$.

4. Once the solution has dissolved, filter it using a $0.22 \mu \mathrm{m}$ syringe filter or a bottle top filter depending on the volume.
Importantly, do not autoclave the fibrinogen solution as this will destroy the fibrinogen.

NOTE: This part of the protocol can take between 2 to $5 \mathrm{~h}$ depending on the amount of stock solution, this time should be taken into consideration during the experimental setup.

\section{Coating inserts with collagen prior to seeding the hydrogels onto the inserts}

1. In a laminar flow hood or a tissue culture hood, using sterilized tweezers, remove inserts from the plate and place inverted onto the lid of the plate.

2. Prepare a $100 \mathrm{~mL}$ of $20 \mathrm{mM}$ glacial acetic acid stock solution by adding $115 \mu \mathrm{L}$ of glacial acetic acid to $25 \mathrm{~mL}$ of $\mathrm{dH}_{2} \mathrm{O}$ and adjust to a final volume of $100 \mathrm{~mL}$ with $\mathrm{dH}_{2} \mathrm{O}$. Filter the solution using a $0.22 \mu \mathrm{m}$ syringe filter. Stock solution can be stored at RT.

3. Prepare $2 \mathrm{~mL}$ of a $100 \mu \mathrm{g} / \mathrm{mL}$ collagen solution from a 5 $\mathrm{mg} / \mathrm{mL}$ collagen solution by adding $40 \mu \mathrm{L}$ of the $5 \mathrm{mg} / \mathrm{mL}$ collagen solution to $1.960 \mathrm{~mL}$ of the $20 \mathrm{mM}$ glacial acetic acid stock solution prepared in 2.2 .

4. Coat the inserts with the $100 \mu \mathrm{g} / \mathrm{mL}$ collagen solution prepared in 2.3 by pipetting $100 \mu \mathrm{L}$ of the solution onto each insert. Let inserts air dry within the laminar flow hood or tissue culture hood for 2 to $3 \mathrm{~h}$.

5. Once inserts have dried wash each insert $3 x$ with PBS. Add $1 \mathrm{~mL}$ of PBS to each well of a 12 well plate, place the inserts with collagen coating facing down into the wells, remove PBS from the well and repeat the procedure. Let inserts air dry within the laminar flow hood 1 to $2 \mathrm{~h}$.

CAUTION: Acetic acid is toxic to cells and inserts should be washed thoroughly with PBS. 
6. Add a custom 3D printed spacer over the inserts, this will be necessary once the gels are hanging from the insert to prevent them from touching the bottom well of the plate (Figure 2).

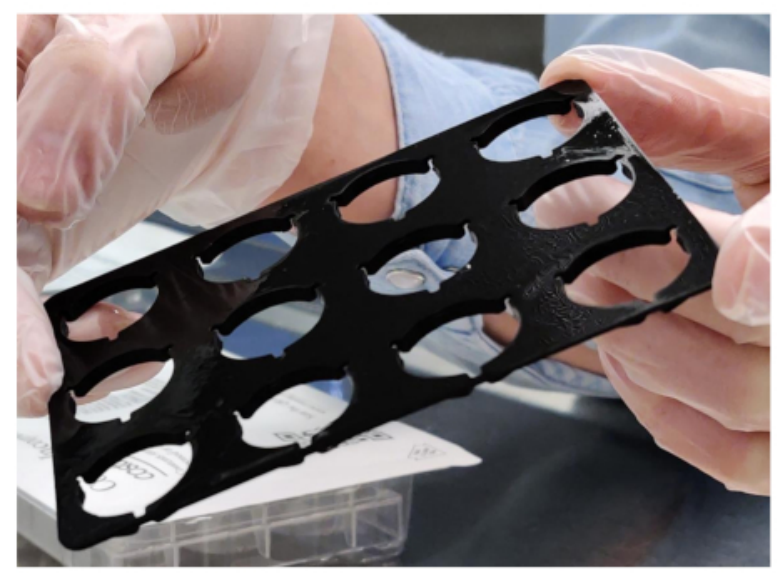

Figure 2: Custom 3D printed spacer Please click here to view a larger version of this figure.

7. Cover the inverted inserts with the bottom part of the plate and place into the incubator until cells are embedded in the hydrogels and ready to be seeded.

\section{Seeding cells embedded in hydrogels onto inserts}

NOTE: Table 1 provides a description of 3 formulations with varying concentrations fibrinogen that will be prepared.

\begin{tabular}{|c|c|c|c|c|c|c|c|c|c|c|c|c|}
\hline Formulation & \begin{tabular}{|c} 
Final \\
Fibrinogen \\
concentration \\
$(\mathrm{mg} / \mathrm{mL})$
\end{tabular} & $\begin{array}{c}\text { Final } \\
\text { Collagen } \\
\text { concentration } \\
(\mathrm{mg} / \mathrm{mL})\end{array}$ & $\begin{array}{l}\text { Cells (LX2 + } \\
\text { HepG2 Co- } \\
\text { culture 1:1) }\end{array}$ & $\begin{array}{l}\text { Stage of } \\
\text { the liver }\end{array}$ & $\begin{array}{l}\text { Literature } \\
\text { liver } \\
\text { stiffness } \\
\text { values }(\mathrm{kPa})\end{array}$ & $\begin{array}{l}\text { Model } \\
\text { Stiffness } \\
\text { value from } \\
\text { Rheology } \\
\text { (KPa) }\end{array}$ & Formulation & $\begin{array}{l}\text { Fibrinogen } \\
\text { to add (mL) }\end{array}$ & $\begin{array}{l}\text { Collagen } \\
\text { to add (mL) }\end{array}$ & $\begin{array}{c}10 \% \\
\text { DMEM (mL) }\end{array}$ & $\begin{array}{c}\text { Thrombin } \\
(\mu \mathrm{L})\end{array}$ & References \\
\hline 1 & 10 & 2 & $\begin{array}{l}2 \times 10^{6} \\
\text { cells } / \mathrm{mL}\end{array}$ & Fibrosis & $\geq 2$ & 3 & 1 & 1 & 0.8 & 0.2 & 4 & $28 ; 29 ; 30$ \\
\hline 2 & 30 & 2 & $\begin{array}{l}2 \times 10^{6} \\
\text { cells } / \mathrm{mL}\end{array}$ & Cirrhosis & & 6 & 2 & 0.75 & 0.8 & 0.45 & 3 & \\
\hline
\end{tabular}

Formulation one corresponds to the liver during the onset of fibrosis, two cirrhosis and three HCC, the stiffness values for each of these formulations were determined with rheology during the protocol optimization. 


\begin{tabular}{|c|c|c|c|c|c|c|c|c|c|c|c|c|}
\hline 3 & 40 & 2 & $2 \times 10^{6}$ & $\mathrm{HCC}$ & $\geq 10$ & 10 & 3 & 0.25 & 0.8 & 0.95 & 1 & $28 ; 31 ; 32$ \\
\hline
\end{tabular}

Table 1: Description of formulations for seeding cells embedded in hydrogels onto inserts

1. Prepare $1 \mathrm{M}$ sodium hydroxide stock solution by adding $3.99 \mathrm{~g}$ of $\mathrm{NaOH}$ to $100 \mathrm{~mL}$ of $\mathrm{dH}_{2} \mathrm{O}$. The solution can then be filtered using a $0.22 \mu \mathrm{m}$ syringe filter. Store the stock solution at RT.

2. Place the $5 \mathrm{mg} / \mathrm{mL}$ collagen and $10 \mathrm{~mL}$ of $1 \mathrm{M} \mathrm{NaOH}$ on ice.

3. Preheat $50 \mathrm{~mL}$ PBS, $15 \mathrm{~mL}$ trypsin, $70 \mathrm{~mL} 10 \%$ DMEM, and fibrinogen stock solution, prepared in section 1, to 37 ${ }^{\circ} \mathrm{C}$ for $20 \mathrm{~min}$ in a water bath.

4. Prepare the cell suspensions.

1. Wash hepatic stellate cells (LX2) and liver carcinoma (HepG2) cells in T175 culture flasks twice with $10 \mathrm{~mL}$ of PBS.

2. Trypsinize cells with $6 \mathrm{~mL}$ trypsin for $4 \mathrm{~min}$ at $37^{\circ} \mathrm{C}$.

3. Inactivate trypsin with $6 \mathrm{~mL}$ of $10 \%$ DMEM.

4. Collect the cell suspension in $15 \mathrm{~mL}$ tube and centrifuge for $3 \mathrm{~min}$ at $300 \times \mathrm{g}$.

5. After centrifugation, aspirate the supernatant and resuspend each cell line in $5 \mathrm{~mL}$ of $10 \%$ DMEM.

6. Count the cells using an automated cell counter: Add $10 \mu \mathrm{L}$ of each cell suspension to the counting chamber slide and insert the slide into the cell counter. Cell count is displayed as cells $/ \mathrm{mL}$.

7. Dilute the cells from each cell line to $1 \times 10^{6}$ cells per $\mathrm{mL}$ using the cell count in step 3.4.6 into clearly marked $15 \mathrm{~mL}$ tubes. Centrifuge the dilutions for $3 \mathrm{~min}$ at $300 \times g$.
5. After centrifugation, aspirate the supernatant and add 10\% DMEM to each $15 \mathrm{~mL}$ tube according to Table 1 , values provided in the Table is for $2 \mathrm{~mL}$ of each formulation.

6. Neutralize the amount of collagen with $10 \mu \mathrm{L} / \mathrm{mL} \mathrm{NaOH}$ (1 M), and add the neutralized collagen to the cell suspension, the $10 \%$ DMEM present will turn yellow, once the suspension is mixed thoroughly by pipetting with a cut tip it will turn a bright pink.

7. Add fibrinogen to the collagen cell suspension according to Table 1, using a cut pipette tip, mix the suspension thoroughly.

8. Finally add thrombin to collagen-fibrinogen cell suspension, $0.1 \mathrm{KIU}$ thrombin for each $10 \mathrm{mg}$ of fibrinogen.

9. Remove the pre-coated inverted inserts prepared in section 2 from the incubator and using a cut $200 \mu \mathrm{L}$ pipette tip, pipette $200 \mu \mathrm{L}$ of the prepared suspension onto the designated inserts. Allow the gels to crosslink for $15 \mathrm{~min}$ within the laminar flow hood.

10. After $15 \mathrm{~min}$, gently place the bottom section of the plate over the gels and move them to the incubator to allow the gels to crosslink at $37^{\circ} \mathrm{C}$ for $45 \mathrm{~min}$.

11. Once the gels have crosslinked, invert the inserts again and add $2 \mathrm{~mL}$ of $10 \%$ DMEM to each of the bottom wells of the plate. 


\section{Seeding endothelial cells}

1. Preheat $25 \mathrm{~mL}$ hanks balanced salt solution (HBSS), 10 $\mathrm{mL}$ trypsin, $10 \mathrm{~mL}$ trypsin inhibitor and $50 \mathrm{~mL}$ endothelial growth medium, to $37^{\circ} \mathrm{C}$ for $20 \mathrm{~min}$ in a water bath .

2. Prepare the endothelial (HUVEC) cell suspension.

1. Wash HUVEC cells in T175 culture flasks twice with $10 \mathrm{~mL}$ HBSS.

2. Trypsinize cells with $6 \mathrm{~mL}$ trypsin for $4 \mathrm{~min}$ at $37^{\circ} \mathrm{C}$. Inactivate trypsin with $6 \mathrm{~mL}$ trypsin inhibitor. Collect the cell suspension in $15 \mathrm{~mL}$ of tube and centrifuge for $3 \mathrm{~min}$ at $200 \times \mathrm{g}$.

3. After centrifugation aspirate the supernatant and suspend the cells in $5 \mathrm{~mL}$ endothelial growth medium.

4. Count the cells as previously described in 3.4.6 using an automated cell counter.

5. Using the cell count from the cell counter, prepare seeding density of $1.0 \times 10^{4}$ cells $/ \mathrm{mL}$ in endothelial growth medium.

3. Seed $500 \mu \mathrm{L}$ of the HUVEC cell suspension into each well of the top part of the insert to have a final volume of 5.0 $\times 10^{3}$ cells per insert.

\section{Maintenance}

1. Replace the growth medium every second day, aspirate spent growth medium from both the well and the insert. Add $2 \mathrm{~mL} \mathrm{10 \%} \mathrm{DMEM} \mathrm{to} \mathrm{the} \mathrm{wells} \mathrm{containing} \mathrm{the} \mathrm{gel}$ and $0.5 \mathrm{~mL}$ endothelial growth medium to the inserts containing the HUVEC cells.

2. Maintain the model for 21 days prior to experimentation.

\section{Rheology}

1. Measure storage moduli of gel formulations to indicate stiffness values using a rheometer, by performing frequency sweeps from $0.1-20 \mathrm{~Hz}$ at $0.267 \%$ and $37^{\circ} \mathrm{C}$, with a constant axial force of $0.1 \mathrm{~N}$ using an $8 \mathrm{~mm}$ diameter parallel plate stainless steel geometry.

\section{Viability and drug response}

1. Determine the drug response and viability in $2 \mathrm{D}$ cocultures and 3D model.

1. Seed HepG2 $\left(5.0 \times 10^{3}\right.$ cells $\left./ \mathrm{mL}\right)$ and LX2 $\left(5.0 \times 10^{3}\right.$ cells $/ \mathrm{mL}$ ) cells in a 1:1 ratio for the $2 \mathrm{D}$ co-culture into a black clear bottom 96 -well plates at a seeding density of $1.0 \times 10^{4}$ cells $/ \mathrm{mL}$. Allow cells to attach overnight.

2. Setup the $3 D$ model to correspond to a cirrhotic environment with a stiffness value of $6 \mathrm{kPa}$. Maintain the model for 21 days prior to Doxorubicin treatment.

2. Two hours prior to doxorubicin treatment, aspirate the culture medium from both the $2 \mathrm{D}$ and $3 \mathrm{D}$ model. Wash both models twice with PBS. Add the starvation medium (DMEM supplemented with $1 \% \mathrm{v} / \mathrm{v}$ antimycotic antibiotic solution) to the $2 \mathrm{D}$ co-culture ( $200 \mu \mathrm{L}$ per well) and to the $3 \mathrm{D}$ model $(2 \mathrm{~mL}$ to the wells containing the hydrogel and $500 \mu \mathrm{L}$ to the insert).

3. Administer doxorubicin to the both the $2 \mathrm{D}$ and the 3D model. Dosages are as follows: $0.5,1$ and 1.5 $\mathrm{mM}$ corresponding to the IC25, 50 and 75 values, respectively. Treat both models for $72 \mathrm{~h}$.

NOTE: Doxorubicin, a topoisomerase II inhibitor, is one of the first chemotherapeutic drugs used for HCC and is 
also one of the most active chemotherapeutic agents in the treatment of $\mathrm{HCC}^{33}, 34$.

4. After $72 \mathrm{~h}$, aspirated culture medium from both the $2 \mathrm{D}$ and $3 \mathrm{D}$ model. Ensure that any remaining culture medium is removed by washing both models twice with PBS.

5. Prepare AlamarBlue according to the manufacturer recommendations and add to the wells of the $2 \mathrm{D}$ and $3 \mathrm{D}$ model. Add $150 \mu \mathrm{L}$ per well for the $2 \mathrm{D}$ culture and $2 \mathrm{~mL}$ per well and $500 \mu \mathrm{L}$ per insert for 3D culture. Incubated overnight at $37^{\circ} \mathrm{C}$.

6. Following incubation transfer $150 \mu \mathrm{L}$ of the AlamarBlue from each well of the 3D setup into a black clear bottom 96-well plate. AlamarBlue can be read directly from the plate for the the $2 \mathrm{D}$ model.

7. Read the fluorescence with a microplate reader at excitation wavelength and emission wavelength of 485 and $550 \mathrm{~nm}$, respectively.

8. Calculate the percentage cell viability in both models using the following formula:

$\%$ Cell viability $=\frac{\text { Fluorescence sample -Average Fluorescence Blank }}{\text { Average Fluorescence Control -Average Fluorescence Blank }} \times 100$

\section{Representative Results}

Concentration ranges and seeding volume

Protocol optimization to obtain the final functioning protocol occurred according to the schematic diagram presented in
Figure 3. Two physiologically relevant hydrogels, Collagen type I and Fibrinogen, was identified by means of a literature search $^{35,36}$. Starting with rat tail collagen type I, a range of concentrations $(4,3,2$ and $1 \mathrm{mg} / \mathrm{mL})$ was seeded onto inverted inserts to determine their ability to successfully adhere to the insert once inverted again. All concentrations within this range were able to form gels, however collagen gels appeared flattened and had various air bubbles trapped within them because of handling and pipetting, see Figure 4 and Figure 5. To determine the optimal seeding volume to improve the quality of the collagen gel, a range of seeding volumes (100, 150 and $200 \mu \mathrm{L}$ ), was seeded onto inverted inserts, see Figure 5. The seeding volume had no influence on the appearance of the gel or the presence of bubbles within the gel. Accordingly, it was decided that $200 \mu \mathrm{L}$ was the optimal seeding volume producing the fullest gels. Fibrinogen was also evaluated for its ability to produce a gel that could adhere to an insert for a prolonged time period. A concentration range $(70,50,40,30,20,10,5,1 \mathrm{mg} / \mathrm{mL})$ was prepared and seeded at a volume of $200 \mu \mathrm{L}$ onto the lid of a 12-well plate, see Figure 6. Within 20 min after seeding all the concentrations were able to successfully form a gel. However, the concentrations 5 and $1 \mathrm{mg} / \mathrm{mL}$ was excluded as the gels formed had a fluid like consistency and had started to detach from the lid after being kept overnight at $37^{\circ} \mathrm{C}$. 


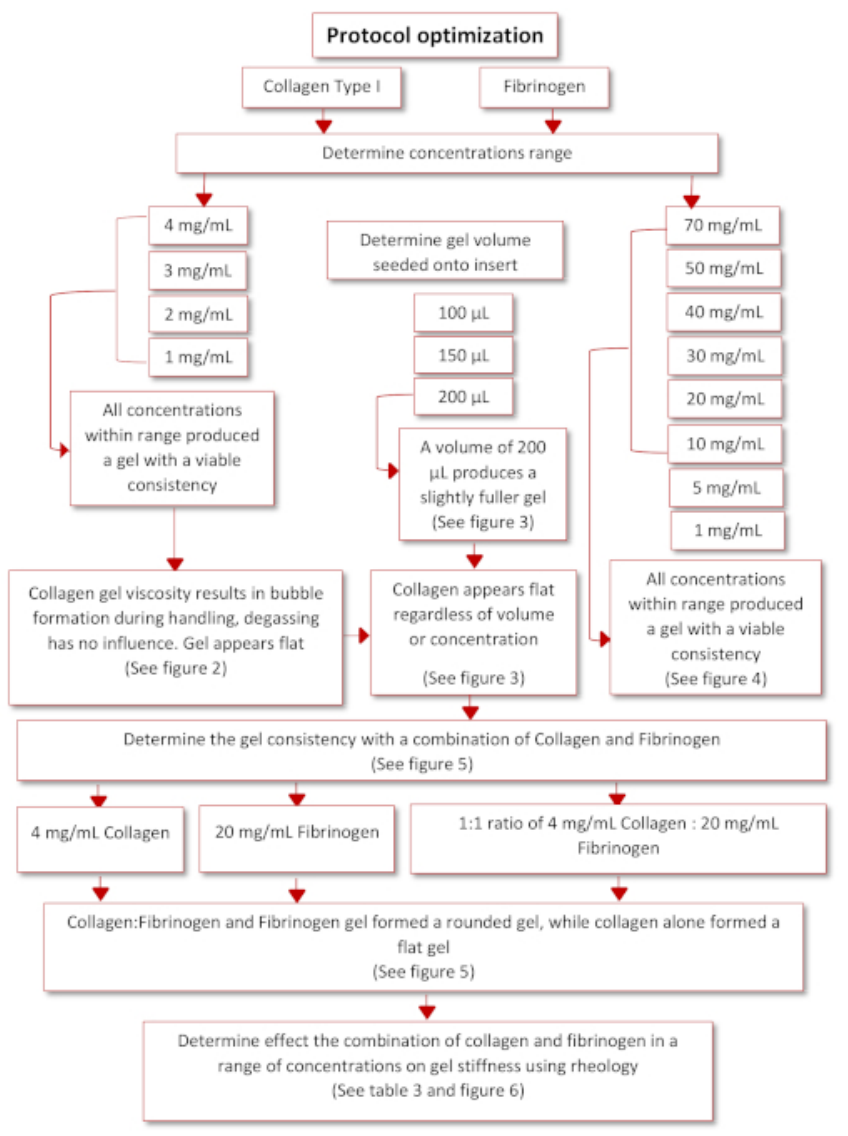

Figure 3: Schematic diagram of protocol optimization. Please click here to view a larger version of this figure. 


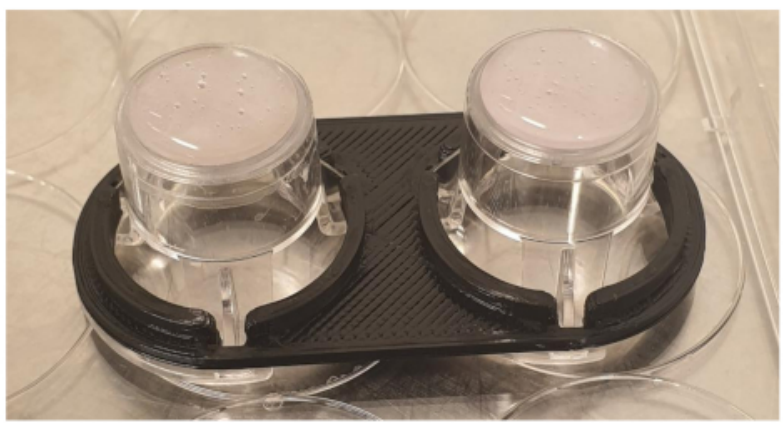

Figure 4: Collagen gels $4 \mathrm{mg} / \mathrm{mL}$ containing $1.0 \times 10^{5}$ cells $/ \mathrm{mL}$ seeded onto inserts showing bubbles present in the gel. Insert on the left been degassed on ice for $15 \mathrm{~min}$, while insert on the right has not been degassed. Degassing did not have any effect on the bubbles present in the gels. Please click here to view a larger version of this figure.

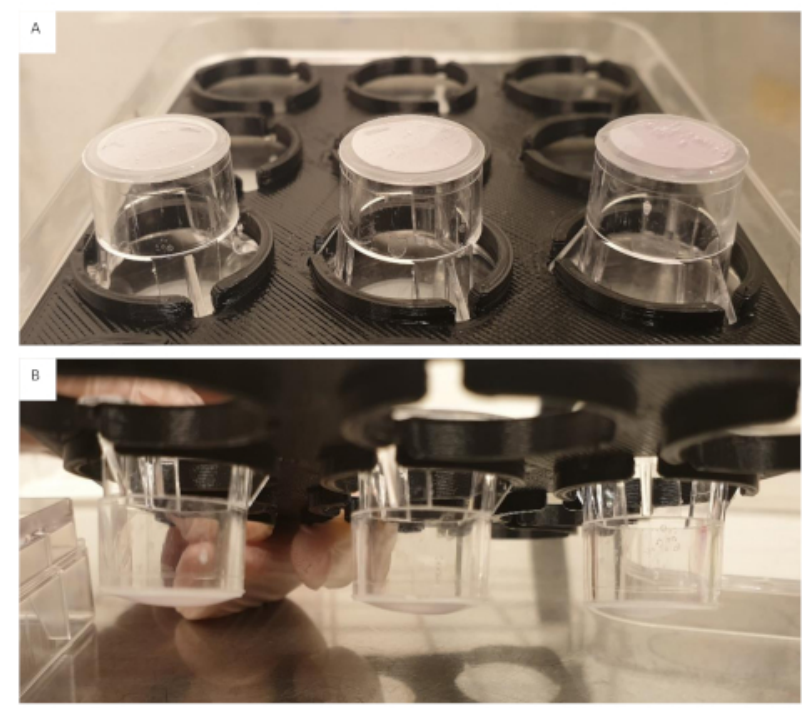

Figure 5: Collagen gels $4 \mathrm{mg} / \mathrm{mL}$ containing $1.0 \times 10^{5}$ cells $/ \mathrm{mL}$ seeded onto inserts in varying volumes. (A) Insert on the left $100 \mu \mathrm{L}$, middle $150 \mu \mathrm{L}$ and right $200 \mu \mathrm{L}$, directly after seeding. Bubbles in the gels were still present. (B) Insert on the left $200 \mu \mathrm{L}$, middle $150 \mu \mathrm{L}$ and right $100 \mu \mathrm{L}$, after 60 min crosslinking. All gels regardless of volume still appear flat. Please click here to view a larger version of this figure. 


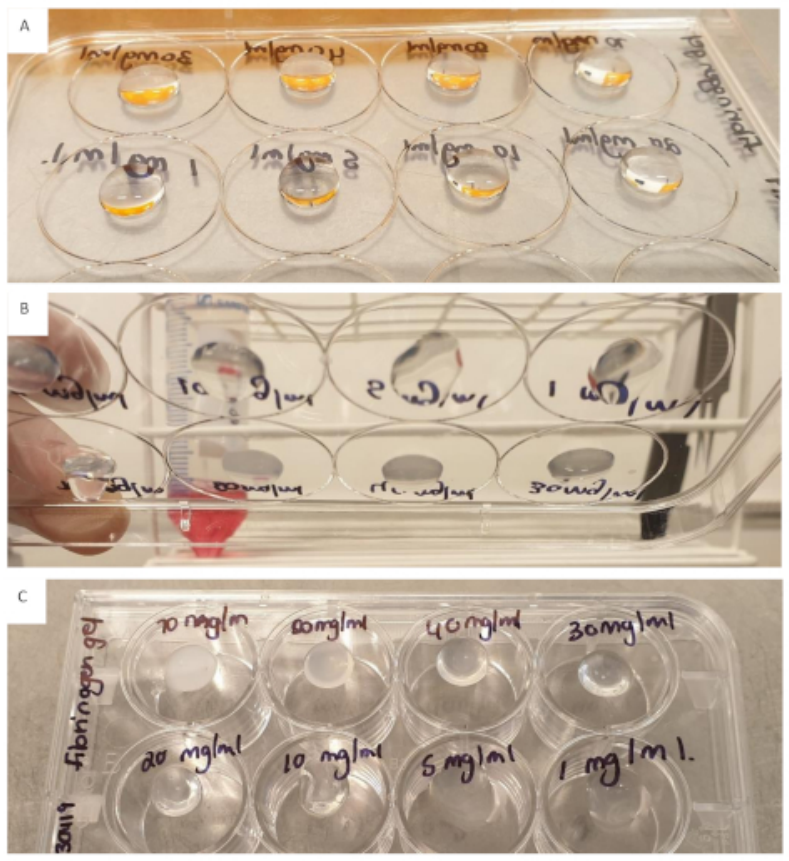

Figure 6: Fibrinogen $(200 \mu \mathrm{L})$ in a concentration range from 70 to $1 \mathrm{mg} / \mathrm{mL}$ seeded onto the lid of a 12-well plate. (A) Gels directly after seeding. (B) Gels $20 \mathrm{~min}$ after seeding. (C) Gels kept overnight. All gels appear well rounded, the $5 \mathrm{mg} / \mathrm{mL}$ and $1 \mathrm{mg} / \mathrm{mL}$ gels were excluded as they appeared to have a more fluid consistency $20 \mathrm{~min}$ after seeding and had started to detach from the lid after being kept overnight. Please click here to view a larger version of this figure.

\section{Combination collagen and fibrinogen}

Based on the results from the collagen and fibrinogen concentration ranges the effect of combining the collagen and fibrinogen was evaluated. Three inserts were setup with the following, $4 \mathrm{mg} / \mathrm{mL}$ collagen, $20 \mathrm{mg} / \mathrm{mL}$ fibrinogen and a $1: 1$ ration of collagen $(4 \mathrm{mg} / \mathrm{mL})$ and fibrinogen $(20 \mathrm{mg} /$ $\mathrm{mL}$ ), see Figure 7. Directly after seeding the hydrogels, we observed that the insert with collagen alone still had a flat appearance combined with the occurrence of bubbles within the gel. The inserts with fibrinogen produced a full and rounded gel, so did the insert with the combination of collagen and fibrinogen. After cross linking at $37^{\circ} \mathrm{C}$ for $60 \mathrm{~min}$, all gels had attached to the insert and remained attached following overnight incubation at $37^{\circ} \mathrm{C}$. 


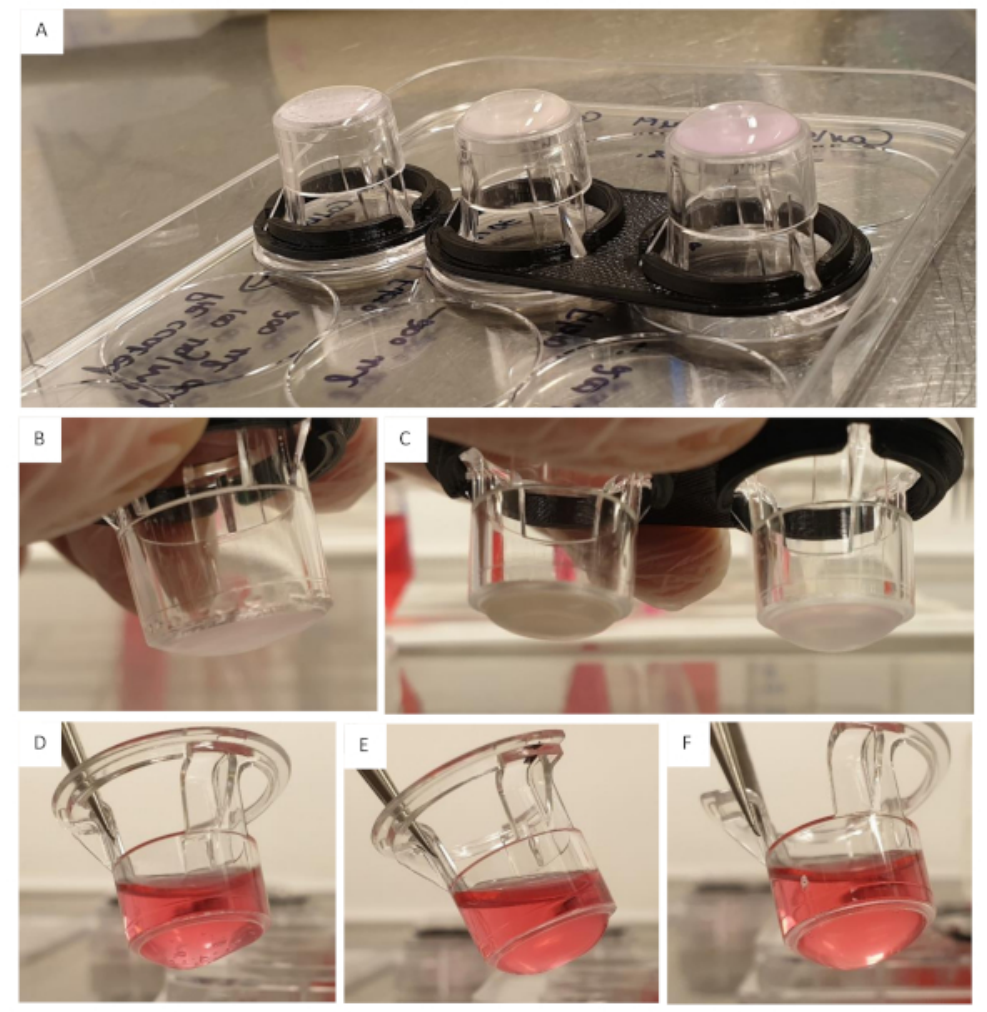

Figure 7: Effect of the combination of collagen and fibrinogen. (A) Collagen $4 \mathrm{mg} / \mathrm{mL}$ seeded onto insert on the left, fibrinogen $20 \mathrm{mg} / \mathrm{mL}$ seeded onto insert in the middle and collagen $4 \mathrm{mg} / \mathrm{mL}$, fibrinogen $20 \mathrm{mg} / \mathrm{mL}$ (1:1 ration) seeded onto insert on the right. All gels seeded at a volume of $200 \mu \mathrm{L}$ containing $1.0 \times 10^{5}$ cells $/ \mathrm{mL}$, all gels were crosslinked for $60 \mathrm{~min}$ at $37^{\circ} \mathrm{C}$. (B) Collagen $4 \mathrm{mg} / \mathrm{mL} 60 \mathrm{~min}$ after crosslinking, gel appeared flat and had bubbles. (C) Insert on the left fibrinogen $20 \mathrm{mg} / \mathrm{mL}$, gel appear rounded, no bubbles present, insert on the right collagen $4 \mathrm{mg} / \mathrm{mL}$, fibrinogen $20 \mathrm{mg} / \mathrm{mL}$ gel, gel is well rounded with no bubbles. (D) Collagen $4 \mathrm{mg} / \mathrm{mL}$ gel after being kept overnight at $37^{\circ} \mathrm{C}$, gel still contained a large amount of bubbles, some swelling of the gel has occurred. (E) Fibrinogen $20 \mathrm{mg} / \mathrm{mL}$ kept overnight at $37^{\circ} \mathrm{C}$. (F) Collagen 4 $\mathrm{mg} / \mathrm{mL}$, fibrinogen $20 \mathrm{mg} / \mathrm{mL}$ gel kept overnight at $37^{\circ} \mathrm{C}$. Please click here to view a larger version of this figure.

\section{Determining cell seeding density}

Based on the previous experience of working with hydrogels an experiment was setup to determine the optimal cell seeding density (data not shown) ${ }^{37}$. Cells were embedded into a combination of collagen and fibrinogen in the following concentration range $\left(7.5 \times 10^{5}, 8.5 \times 10^{5}, 9.5 \times 10^{5}, 1.0 \times\right.$
$10^{6}, 1.5 \times 10^{6}$ and $2.0 \times 10^{6}$ cells $\left./ \mathrm{mL}\right), 2.0 \times 10^{6} \mathrm{cells} / \mathrm{mL}$ was found to be the optimal seeding density.

\section{Rheology}

Ten formulations of the fibrinogen and collagen hydrogel combinations were evaluated by means of rheology, see Table 2. The aim was to determine which of these formulations could mimic liver stiffness seen during the 
development of HCC. Literature provided known liver stiffness values for rats, mice and humans during fibrosis, cirrhosis and $\mathrm{HCC}$ and the aim was to get as close as possible to these values $28,29,30,31,32$. The ten formulations as set out in Table 2 was prepared in triplicate and the storage modulus of each were determined using a rheometer, results shown in Figure 8.

\begin{tabular}{|c|c|c|}
\hline Formulation & Fibrinogen (mg/ml) & Collagen (mg/ml) \\
\hline 1 & 60 & 2 \\
\hline 2 & 50 & 2 \\
\hline 3 & 40 & 2 \\
\hline 4 & 30 & 2 \\
\hline 5 & 20 & 2 \\
\hline 6 & 10 & 2 \\
\hline 7 & 20 & 5 \\
\hline 8 & 20 & 4 \\
\hline 9 & 20 & 3 \\
\hline 10 & 20 & 1 \\
\hline
\end{tabular}

Table 2: Collagen and fibrinogen combinations in various concentrations evaluated with Rheology to determine stiffness values

Figure 8: Hydrogel stiffness values for Collagen and fibrinogen combinations in various concentrations evaluated with Rheology. Storage modulus and loss modulus were determined at $37^{\circ} \mathrm{C}$ and $1 \mathrm{~Hz}$ by means of a Discovery $\mathrm{HR}-2$ Hybrid Rheometer $(n=3$, Error bars $=S D)$. Please click here to view a larger version of this figure. 
From these ten formulas three was chosen to proceed with. These included $2 \mathrm{mg} / \mathrm{mL}$ collagen type I and $10 \mathrm{mg} / \mathrm{mL}$ fibrinogen corresponding to liver stiffness values at the onset of fibrosis, $2 \mathrm{mg} / \mathrm{mL}$ collagen type I and $30 \mathrm{mg} / \mathrm{mL}$ fibrinogen corresponding to cirrhosis and $2 \mathrm{mg} / \mathrm{mL}$ collagen type I and $40 \mathrm{mg} / \mathrm{mL}$ fibrinogen corresponding to HCC, see Figure 9.

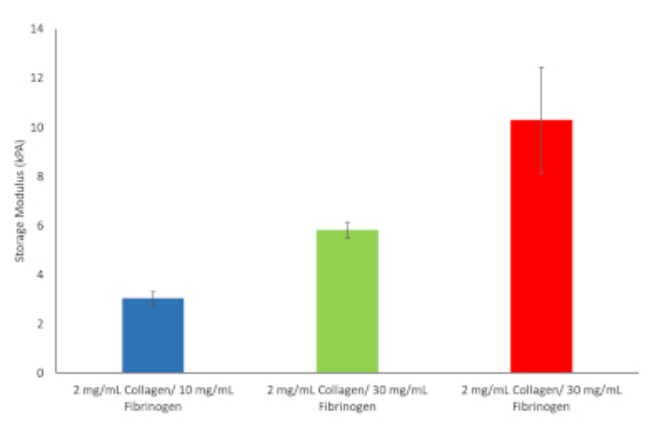

Figure 9: Hydrogel stiffness values for various Fibrinogen/Collagen hydrogel formulations chosen to continue with. Storage modulus and loss modulus were determined at $37^{\circ} \mathrm{C}$ and $1 \mathrm{~Hz}(n=3$, Error bars $=\mathrm{SD})$. Please click here to view a larger version of this figure.

Viability, drug response and metastatic potential

The results from the AlamarBlue assay showed an overall reduced cell viability within the $2 \mathrm{D}$ co-culture, lower than expected based on the known reported IC 25, 50 and 75 values, when compared to the untreated control, see Figure 10. This may be attributed to the LX2 cells in our co-culture that are more sensitive to Doxorubicin treatment. However, in our 3D model we noticed and increase in doxorubicin resistance, confirming the decrease in chemotherapeutic potential often seen in 3D model systems. Statistical significance compared to controls was assessed using the Student $\mathrm{T}$ test (two-tailed), with $\mathrm{P}<0.05$ considered significant. 


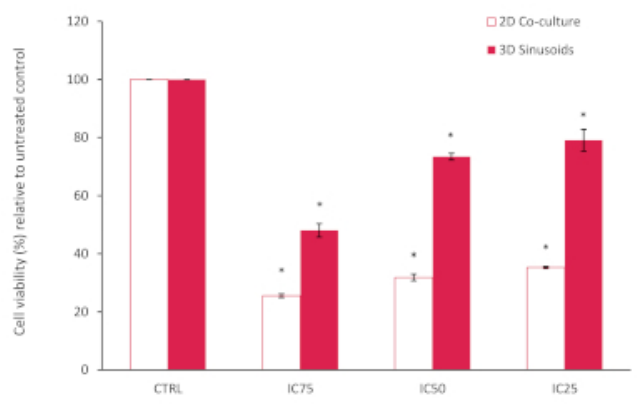

Figure 10: Percentage cell viability of a 2D co-culture model compared to the 3D model after treatment with Doxorubicin at various concentrations for a period of $\mathbf{7 2 h}$. Results normalized relative to the untreated control $(n=3$, error bars $=S D)\left({ }^{*}=p<0.0001\right)$. Please click here to view a larger version of this figure.

The gel constructs were visually inspected daily using a light microscope to follow cell growth within different concentrations of the hydrogels. Cells filled up the hydrogels in a homogeneous and compact way, from day 7 spheroids started to assemble within the matrix.

\section{Discussion}

This protocol describes the development of a method to create a biomimetic model for HCC. A clear workflow has been established and the critical steps involved identified. These critical steps include, preparation of the fibrinogen stock solution, coating the inserts with collagen and seeding the cells imbedded into the hydrogel. During the preparation of the fibrinogen stock solution it is important to add the fibrinogen in smaller increments at higher concentrations. This will not only reduce the time it takes for the fibrinogen to dissolve but will also prevent the fibrinogen from gelling inconsistently and prematurely as seen in Figure 11. The preparation of the fibrinogen gel takes a considerable amount of time and this may influence the overall experimental success. Results indicates that once the fibrinogen gel starts to gel inconsistently it is best to discard it. The inserts should be coated with collagen, washed with PBS and dried within the laminar flow hood prior to seeding the cells embedded in hydrogels. Failure to ensure that the inserts are dry will result in the hydrogels spilling over the edges of the insert, resulting in an uneven gel. Unevenness of the gel will ultimately influence results where diffusion is a factor. 

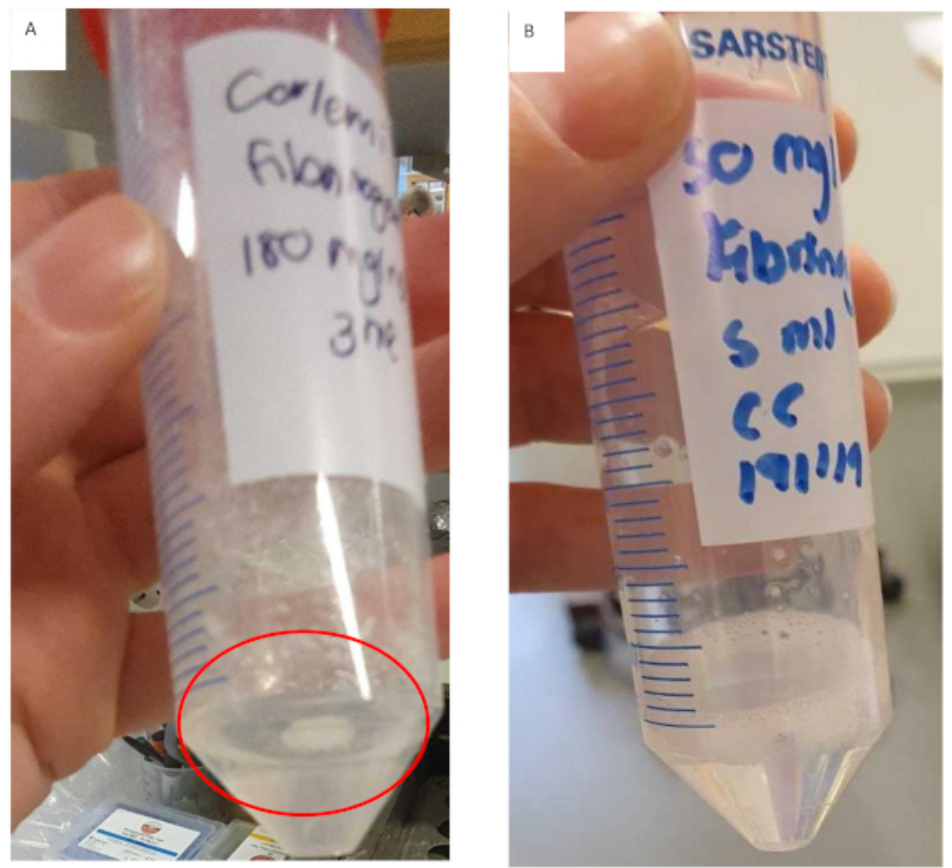

Figure 11: Preparation of fibrinogen gel for fibrinogen/collagen hydrogel formulations. (A) Fibrinogen gel solution that has formed clumps and started to gel prematurely with undissolved fibrinogen adhering to the tube. (B) Fibrinogen gel solution that has dissolved completely, solution is clear and slightly more viscous. Please click here to view a larger version of this figure.

It is recommended to work as fast as possible while seeding the hydrogel cell suspension onto the inserts, as the fibrinogen component will start to crosslink with the addition of thrombin. Prepare smaller working volumes at a time when working with gel suspensions at higher concentrations to prevent the gel from crosslinking while seeding. The latter will have an effect on the distribution and the amount of gel seeded onto each well. The order of adding the components is critical, in this protocol we provided a streamlined workflow to prevent gels from crosslinking prematurely. Due to the viscosity of the hydrogel gel suspension working with a cut pipette tip is advised during mixing and measuring. When mixing the suspension ensure that this is done quickly and evenly to create a homogenous suspension. Uneven mixing will result in a heterogeneous gel which will negatively affect results, see Figure 12. 


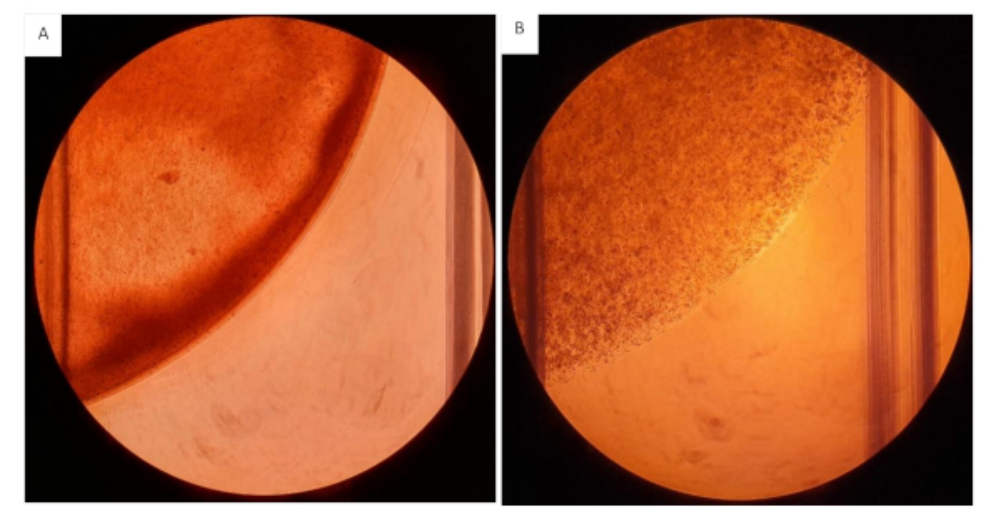

Figure 12: Collagen/fibrinogen gels seeded onto 12 well plates. All gels seeded at a volume of $200 \mu \mathrm{L}$ containing $2 \mathrm{mg} /$ $\mathrm{mL}$ Collagen and $20 \mathrm{mg} / \mathrm{mL}$ Fibrinogen with $2.0 \times 10^{6}$ cells $/ \mathrm{mL}$. (A) Hydrogel gel with heterogeneous consistency, visible uneven distribution of the hydrogels. (B) Hydrogels homogenously mixed. Please click here to view a larger version of this figure.

Following the protocol optimization, the model was evaluated to determine the models bio-physical properties. Rheology data showed that our model, composed of physiologically relevant extracellular matrix components namely collagen type I and fibrinogen, was able to mimic the biophysical properties of a fibrotic, cirrhotic and HCC liver $^{28}, 29,30,31,32$. Recapitulating liver stiffness in 3D models for HCC is of considerable importance and is often overlooked during model development. Increased liver stiffness is related to chemotherapeutic resistance, proliferation, migration, and dormancy within in $\mathrm{HCC}^{38}$. While the activation of hepatic stellate cells in HCC is associated with increased extracellular matrix rigidity, with several signaling pathways associated with these hepatic stellate cells showing mechanosensitivity ${ }^{39}$.

The inclusion of stroma associated cells such as hepatic stellate cells and endothelial cell in the development of 3D models for HCC has become increasingly relevant.
Studies show that multicellular spheroids composed of hepatic stellate and HCC cells resulted in increased chemotherapeutic resistance and invasive migration, while mimicking HCC tumor appearance in vivo, when compared to a PXT mice model and human HCC tissue samples ${ }^{17}$. A similar study by Jung et al., 2017 found multicellular spheroid consisting of hepatocellular carcinoma (Huh-7) and endothelial (HUVEC) cells promoted vascularization and aggressiveness ${ }^{22}$. These spheroids showed viability at significantly higher concentrations of doxorubicin and sorafenib when compared to Huh-7 monoculture spheroids $^{22}$. The evaluation of our model's viability and response to doxorubicin, with stiffness values corresponding to that of $\mathrm{HCC}$ and the inclusion of stroma associated cells (LX2 and HUVEC), showed a similar decreased in response to chemotherapeutics when compared to a $2 \mathrm{D}$ co-culture model. Thus, effectively mimicking drug resistance typically seen in patients and other 3D HCC models. 
As this is a modular system the model can be fortified by the addition of other extracellular matrix components namely, laminin and hyaluronic acid. Alternatively, the current hydrogels used within this model can be replace by synthetic hydrogels such as sodium alginate or chitosan. Further modifications to the current model can be the substitution of the cell lines with primary cell cultures to produce an even more physiologically relevant model or using combinations of other tumor and stromal cell lines.

We have thus successfully developed a 3D model with tunable bio-physical properties for studying tumor-stroma interactions in HCC. We have found our model to be more representative of the in vivo situation when compared to traditional 2D cultures in response to doxorubicin. However, there is still much to be done, we hope to extensively characterize this model and explore the model as a possible metastatic platform to answer more complex and pressing questions that remain in the study HCC.

\section{Disclosures}

The authors have nothing to disclose.

\section{Acknowledgments}

This research was funded through grants obtained from the Swedish Cancer Foundation (Cancerfonden, CAN2017/518), the Swedish society for medical research (SSMF, S17-0092), the O.E. och Edla Johanssons foundation and the Olga Jönssons foundation. These funding sources were not involved in the study design; collection, analysis and interpretation of data; writing of the report; and in the decision to submit the article for publication. 3D printing of custom designed spacers used in this protocol was performed at U-PRINT: Uppsala University's 3D-printing facility at the Disciplinary Domain of Medicine and Pharmacy, U-
PRINT@mcb.uu.se. We would like to thank Paul O'Callaghan for his valuable input on our project.

\section{References}

1. Galle, P. R. et al. EASL Clinical practice guidelines: Management of hepatocellular carcinoma. Journal of Hepatology. 69, 182-236 (2018).

2. Marquardt, J. U., Andersen, J. B., Thorgeirsson, S. S. Functional and genetic deconstruction of the cellular origin in liver cancer. Nature Reviews Cancer. 15, 653-667 (2015).

3. Balogh, J. et al. Hepatocellular Carcinoma: A review. Journal of Hepatocellular Carcinoma. 3, 41-53 (2016).

4. Perumpail, R. B., Womg, R. J., Ahmed, A., Harrison, S. A. Hepatocellular carcinoma in the setting of non-cirrhotic non-alcoholic fatty liver disease and the metabolic syndrome: US experience. Digestive Diseases and Science. 60, 3142-3148 (2016).

5. Baglieri, J., Brenner, D.A., Kisseleva, T. The role of fibrosis and liver associated fibroblasts in the pathogenesis of hepatocellular carcinoma. International Journal of Molecular Sciences. 20, 1723 (2019).

6. Arriazu, E. et al. Extracellular matrix and liver disease. Antioxidants \& Redox Signaling. 21 (7), 1078-1097 (2014).

7. Malarkey, D. E., Johnson, K., Ryan, L., Boorman, G., Maronpot, R. R. New insight into functional aspects of liver morphology. Toxicologic Pathology. 33, 27-34 (2005).

8. Moreira, R. K. Hepatic stellate cells and liver fibrosis. Archive of Pathology and Lab Medicine. 131, 1728-1734 (2007). 
9. Hernandez-Gea, V., Toffanin, S., Friedman, S. L., Llovet, J. M. Role of the microenvironment in the pathogenesis and treatment of hepatocellular carcinoma. Gastroenteroloy. 144, 512-527 (2013).

10. Amicone, L., Marchetti, A. Microenvironment and tumor cells: two targets for new molecular therapies of hepatocellular carcinoma. Translational Gastroenterology and Hepatology. 3, 24 (2018).

11. Rawal, P. et al. Endothelial cell-derived TGF-B promotes epithelial-mesenchymal transition via CD133 in HbxInfected Hepatoma cells. Frontiers in Oncology. 9 (308), 1-9 (2019).

12. Yoo, J. E. et al. Progressive enrichment of stemness features and tumour stromal alterations in multistep hepatocarcinogenesis. PLoS One. 12 (3) e0170465 (2017).

13. Landry, B. D. et al. Tumor-stroma interactions differentially alter drug sensitivity based on the origin of stromal cells. Molecular Systems Biology. 14, e8332 (2018).

14. Le, B. D. et al. Three-dimensional hepatocellular carcinoma/fibroblast model on a nanofibrous membrane mimics tumor cell phenotypic changes and anticancer drug resistance. Nanomaterials. 8 (64), 1-11 (2018).

15. Lv, D., Hu, Z., Lu, L., Lu, H., Xu, X. Three-dimensional cell culture: A powerful tool in tumor research and drug discovery (Review). Oncology Letters. 14, 6999-7010 (2017).

16. Hoarau-Véchot J., Rafii A., Touboul, C., Pasquier, J. Halfway between 2D and animal models: Are 3D cultures the ideal tool to study cancer-microenvironment interactions? International Journal of Molecular Sciences. 19 (181), 1-24 (2018).

17. Khawar, I. A. et al. Three Dimensional Mixed-Cell Spheroids Mimic Stroma-Mediated Chemoresistance and Invasive Migration in hepatocellular carcinoma. Neoplasia. 20, 800-812 (2018).

18. Elliott, N. T., Yuan, F. A review of three-dimensional in vitro tissue models for drug discovery and transport studies. Journal of Pharmaceutical Sciences. 100 (1), 59-74 (2010).

19. Nath, S., Devi, G. R. Three-dimensional culture systems in cancer research: focus on tumor spheroid model. Pharmacology Therapy. 163, 94-108 (2016).

20. Zanoni, M. et al. 3D tumor spheroid models for in vitro therapeutic screening: a systematic approach to enhance the biological relevance of data obtained. Scientific Reports. 6, 19103 (2016).

21. Bell, C. C. et al. Characterization of primary human hepatocyte spheroids as a model system for drug-induced liver injury, liver function and disease. Scientific Reports. 6, 25187 (2016).

22. Jung, H.R. et al. Cell spheroids with enhanced aggressiveness to mimic human liver cancer in vitro and in vivo. Scientific Reports. 7, 10499 (2017).

23. Eilenberger, C., Rothbauer, M., Ehmoser, E-K., Ertl, P., Küpcü, S. Effect of spheroidal age on sorafenib diffusivity and toxicity in a 3D hepg2 spheroid model. Scientific Reports. 9, 4863 (2019).

24. Wrzesinski, K., Fey, S. J. After trypsinisation, 3D spheroids of $\mathrm{C} 3 \mathrm{~A}$ hepatocytes need 18 days to reestablish similar levels of key physiological functions to 
those seen in the liver. Toxicology Research. 2 (2), 123-135 (2013).

25. Wrzesinski, K., et al. Human liver spheroids exhibit stable physiological functionality for at least 24 days after recovering from trypsinisation. Toxicology Research. 2 (3), 163-172 (2013).

26. Mazza, G., et al. Decellularized human liver as a natural 3D-scaffold of liver bioengineering and transplantation. Scientific Reports. 5, 13079 (2015).

27. Ma, X. et al. Rapid 3D bioprinting of decellularized extracellular matrix with regionally varied mechanical properties and biomimetic microarchitecture. Biomaterials. 185, 310-321 (2018).

28. Mueller, S., Sandrin, L. Liver stiffness: a novel parameter for the diagnosis of liver disease. Hepatic Medicine: Evidence and Research. 2, 49-67 (2010).

29. Wang, M. H. et al. In vivo quantification of liver stiffness in a rat model of hepatic fibrosis with acoustic radiation force. Ultrasound in Medicine \& Biology. 35 (10), 1709-1721 (2009)

30. Georges, P. C. et al. Increased liver stiffness of the rat liver precedes matrix deposition: implications for fibrosis. American Journal of Physiology - Gastrointestinal and Liver Physiology. 293, G1147-G1154 (2007).

31. Massironi, S. et al. Liver stiffness and hepatocellular carcinoma: is it really useful? Journal of Hepatology. 58, S293 (2013)

32. Singh, S. et al. Liver stiffness is associated with risk of decompensation, liver cancer, and death in patients with chronic liver diseases: A systematic review. Clinical Gastroenterology and Hepatology. 11, 1573-1584 (2013).
33. Yang, T. S., Wang, C. H., Hsieh, R. K., Chen, J. S., Fung, M. C. Gemcitabine and doxorubicin for the treatment of patients with advanced hepatocellular carcinoma: a phase I-II trail. Annals of Oncology. 13, 1771-1778 (2002).

34. Le Grazie, M., Biagini, M. R., Tarocchi, M., Polvani, S., Galli, A. Chemotherapy for hepatocellular carcinoma: the present and the future. World Journal of Hepatology. 9(21), 907-920 (2017)

35. Saneyasu, T., Akhtar, R., Sakai, T. Molecular cues guiding matrix stiffness in liver fibrosis. BioMed Research International. 2016, 1-11 (2016).

36. Zuliani-Alvarez, L., Midwood, K. S. Fibrinogen-related proteins in tissue repair: how a unique domain with common structure controls diverse aspects of wound healing. Advances in Wound Care. 4 (5), 273-285 (2015).

37. Smit, T. et al. Characterization of an alginated encapsulated LS180 spheroid model for anti-colorectal cancer compound screening. ACS Medicinal Chemistry Letters. 11 (5), 1014-1021 (2020).

38. Schrader, J. et al. Matrix stiffness modulates proliferation, chemotherapeutic response, and dormancy in hepatocellular carcinoma cells. Hepatology. 53 (4), 1192-1205 (2011).

39. Lachowski, D. et al. Matrix stiffness modulates the activity of MMP-9 and TIMP-1 in hepatic stellate cells to perpetuate fibrosis. Scientific Reports. 9, 7299 (2018). 